\title{
Three-Year Surveillance of Chickenpox among the Military Community in Taif - KSA: Primary Reporting of an Epidemic Situation
}

\author{
Sherif R. Omar*, Tawfiq Al-Hussaini ${ }^{\dagger}$
}

\begin{abstract}
Objectives: To study the current epidemiology of varicella (chickenpox), and to document the presence of a recent epidemic situation occurring among members of the military troops and their families in Taif area; Kingdom of Saudi Arabia. Methods: A descriptive study was done to evaluate epidemiological data related to chickenpox over the period of three years starting May $1^{\text {st }} 2005$ till April $30^{\text {th }} 2008$. Data were recorded regularly complying with the infectious diseases surveillance protocol set by the Saudi Ministry of Health that considers varicella as one of the notifiable diseases. Results: 205 cases were recorded in the first year, 257 during the second year, and more than 5 fold increase up to 1395 cases during the third year; males constituted $54.7 \%$ of the total number of cases, all age groups were affected mainly between $5-14$ years (46.9\%) and between $15-44$ years $(32.9 \%)$, cases over the age of 15 comprised $35.16 \%$ of the total number. Conclusions: Reported cases of chickenpox increased dramatically in numbers during the third year of the surveillance indicating an epidemic situation. The disease seams to cease being a childhood exclusive disease; as more than one-third of the reported cases were above the age of 15 . The newly introduced childhood compulsory live-attenuated vaccine started nationally in January 2008 is a new hope to reduce burden of the disease within the Saudi community.
\end{abstract}

Keywords: Chickenpox, Varicella, Epidemiology, Age, Taif, Kingdom of Saudi Arabia.

\section{INTRODUCTON}

Chickenpox or Varicella is a common highly contagious disease results from primary infection with varicella zoster virus. The resulting illness is usually mild and self limited, but serious complications and death may occur. ${ }^{1}$ The disease primarily affect children; who inevitably will suffer its

unwanted

health-related consequences. ${ }^{2}$ Furthermore; Chickenpox may lead to the development of serious complications that could be life threatening in the immuno-suppressed patients, neonates, and normal adults in which the risk of varicella pneumonia, encephalitis,

\footnotetext{
"Epidemiology Unit, Department of Preventive Medicine, Al-Hada Armed Forces Hospital, Taif, Kingdom of Saudi Arabia

+ Vaccination Unit, Department of Preventive Medicine, Al-Hada Armed Forces Hospital, Taif, Kingdom of Saudi Arabia
} 
and acute cerebellar ataxia is relatively high. $^{3}$

In early 1995, a live-attenuated varicella vaccine was licensed for public use in different parts of the world. It has been proven to be safe and effective; it markedly changed the epidemiology of varicella decreasing dramatically the number of cases. ${ }^{4}$ Varicella is considered now by many; the most common infection which is preventable by vaccination. ${ }^{5}$

The disease is notifiable in the Kingdom of Saudi Arabia, there was a marked step-wise increase in its incidence during the last years ${ }^{6}$, that in January 2008 enforced the introduction of varicella vaccine into the routine childhood immunization program after a long period of debate against its national application.

By many Authors ${ }^{7}$ the age incidence of the disease showed an upward change over the last two decades, the more the older age groups other than children are affected; the more morbidity and mortality are seen. The only way to stop this uptrend is to use the vaccine on a wide scale during childhood.

Insight into the epidemiology of varicella is important to justify the use of vaccination as a preventive tool against this common disease, and later on to assess the efficacy of this vaccine. This study is an endeavor to demonstrate size of the problem and epidemiology of chickenpox among the military community in Taif Governorate, Kingdom of Saudi Arabia before the introduction of universal vaccination.

\section{Material and Methods}

A descriptive study was performed to assess the epidemiological data related to chickenpox among military troops and their families who contracted the infection locally in Taif Governorate - western provinces, Kingdom of Saudi Arabia. Taif area accommodates around one million 
inhabitants according to the Third National Census of Population and Housing in the year $2004^{8}$, among them; according to the 2007 records 104360 individuals of Saudi nationality are covered with a modern health insurance system offered by the Ministry of Defense to its staff members and their families. The service is delivered through primary health care facilities namely Prince Mansour Hospital for family medicine, Prince Sultan Hospital, and AlHada Hospital. Secondary care is centrally maintained through the 355 bed Al-Hada Hospital. Tertiary care and rehabilitation is offered through a specialized centre.

Contagious diseases are to be reported from these hospitals centrally to the Preventive Medicine Department in AlHada hospital, notification priority is set by means of a protocol enforced by the Saudi Ministry of Health and applied on a national scale. Chickenpox is to be reported on weekly bases following the international epidemiological weeks guide, data related to cases includes: medical ID number, treating and reporting physicians, age, gender, nationality, residence, contact information, primary diagnosis, results of investigations if any, and if there is any complications did happened.

Non-Saudi individuals were excluded from the study as they may contract infection abroad, majority of them are adults constituting part of the expatriate working force, and their immunological background in relation to varicella may be different from the local inhabitants.

Reporting of notifiable diseases to the Preventive Medicine Department is "passive" and relies on accuracy of health care providers within the military health facilities to report infectious diseases occurrence. Data after being recorded are to be later sent to the local health authority in Taif Governorate that collects data from 
different health facilities and reports them to the next national level.

\section{Preliminary stage:}

Data related to varicella according to the above mentioned variables were revised for completion since the start of the recording system; incomplete items were rerecorded after referring to the patient's file that is accessible through a state of the art electronic filing system.

\section{Implementation stage:}

During the last three years; starting May $1^{\text {st }} 2005$ till the end of April 2008; 1857 cases were identified. Collected data from medical records were coded, tabulated and organized. Analysis was done using the Statistical Package for Social Sciences, version 11.5 (SPSS, 2002).

\section{RESULTS}

During the first year of surveillance started May $1^{\text {st }} 2005$ till April 31 $1^{\text {st }} 2006 ; 205$ cases of clinically diagnosed varicella were recorded, slight increase occurred during the second year that took the number of cases to 257 . The third year started May $1^{\text {st }}$ 2007 and ended April 31 2008 showed a 5 fold increase in number of cases up to 1395, the total number recorded during the three years period was 1857 and it provided the basis for the analysis. Overall; incidence rate among this group of people increased from 196.43 to 246.26 and up to 1336.72 per 100.000 individuals during the last year of the surveillance.

Table 1 displays the distribution of incident cases of chickenpox by age group and gender during the study period; male percentage of cases increased from $50.7 \%$ in the first year up to $55.9 \%$ during the third year, with a total percent of 54.7 over the entire duration. All age groups were affected but the predominant involvement was among individuals aged (5-14) and (15-44) years (46.9 and 32.9\%), respectively. Approximately $64.8 \%$ of all notified cases were below the age of 15 , 
children $<5$ years constituted around $17.9 \%$ of the total number of cases, only $2.3 \%$ were over 45 . All reported cases in this study were of Saudi Arabian nationality as non-Saudis were among the exclusion criteria.

Table 2 and Figure 1 show the monthly distribution of cases over the study period. During the first two years of the surveillance; number of monthly cases showed seasonality pattern with higher incidence between March and June, this period of the year accounted for $65.5 \%$ of cases. During the third year; incident cases started to increase during September with an uptrend reached its peak in January and in March, this pattern didn't follow the seasonality seen in prior years and indicates an epidemic situation.

\section{DISCUSSION}

This primary reporting of the notified chickenpox cases among the military community and their families in Taif - KSA showed an increasing incidence during the study period. This finding is in accordance with conclusions published in other literature..$^{6,9,10}$

Male cases in this study were slightly higher than females (54.7\%), most medical literature state that there is now sex difference in the incidence of varicella $a^{11,12}$. Other reports from Saudi Arabia ${ }^{10}$ showed that there is a significant increase in number of cases among males, the possible explanation may be that males seek medical advice more so the case is reported in this culturally conservative community.

Several studies ${ }^{13}$ mentioned that during the pre-vaccination era in the western communities, varicella is most prevalent between the age of 4 and 10 years. Similarly, the most prevalent age group was 5-14 years constituting alone $46.9 \%$ of cases. Other studies ${ }^{14}$ declared that in Western Europe and North America during 
the pre-vaccination time; around $90 \%$ of varicella cases were $<15$ years. On contrary, in this study $64.8 \%$ were $<15$ years, which goes with other reports from the Saudi Arabia demonstrating that 16$25 \%$ of this infection do occur among adults, and $15-20 \%$ of the adult population are seronegative. ${ }^{15}$

Globally, the epidemiology of chickenpox appears to be changing ${ }^{7}$, there has been an unexplained upward shift in the age distribution of cases over the last 20 years. This change has important consequences for the future morbidity and mortality rates, and for the risk of infection in both health care workers and pregnant women. Other reports ${ }^{16}$ mentioned that more cases of varicella are being reported in children below 5 years, and they attributed this change to the increased social mixing among the pre-schoolers that permits a higher opportunity for virus transmission. On the same trend, children below the age of 5 constituted $17.9 \%$ of all cases enrolled in this study, our explanation is that culture of day cares and pre-school nurseries as well as mixing inside shopping areas and malls became more and more popular inside the Saudi community.

We noticed during the first and second year of the surveillance a clear seasonality pattern making the disease incidence more pronounced during the period between March and June. Reports from other Saudi $\operatorname{areas}^{10}$ noticed a similar seasonality mainly during spring and winter seasons. During the current epidemic in Taif area, case numbers didn't follow this seasonality and increased markedly since September and till this report was done.

"Passive surveillance" currently used to report infectious diseases got a potential bias, as it relies on notification by the health care providers. So, cases may be under-estimated especially if high 
proportion of them did not seek health care facilities. A more sensitive way to detect cases is to be defined and assessed.

Our study concludes that there is a dramatic increase in the notified cases diagnosed clinically to have chickenpox, future to assess incidence after vaccination and this increase is a primary alert of a and cost-effectiveness of immunization. running epidemic among the military

community and their families in Taif area KSA. The newly introduced routine immunization will definitely decrease the incidence and severity of the disease. Further studies are to be performed in the

\section{(Figure 1): Cases of Chickenpox over 3 Years}

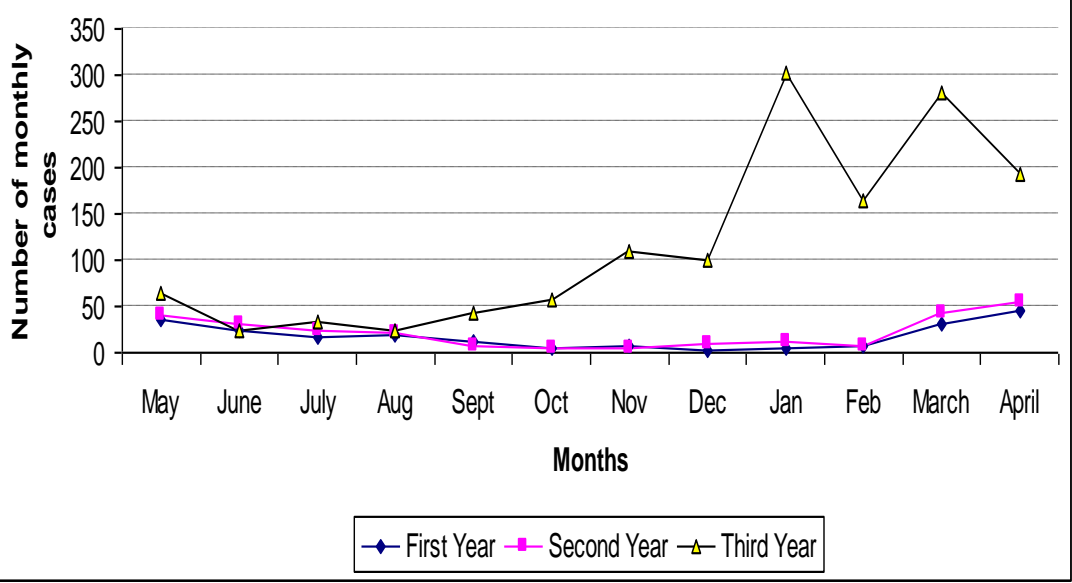

Figure 1: Number of chickenpox cases by the month over a three years period. 
Table 1: Distribution of chickenpox cases by age group and gender among the military community and their families in Taif - KSA over three years period (May 2005 - April 2008)

\begin{tabular}{|c|c|c|c|c|c|c|c|}
\hline \multirow{3}{*}{$\begin{array}{c}\text { AGE } \\
\text { GROUP }\end{array}$} & \multicolumn{6}{|c|}{ GENDER (\%) } & \multirow{3}{*}{ TOTAL } \\
\hline & \multicolumn{2}{|c|}{ First Year } & \multicolumn{2}{|c|}{ Second Year } & \multicolumn{2}{|c|}{ Third Year } & \\
\hline & Male & Female & Male & Female & Male & Female & \\
\hline$<1$ year & 5 & 4 & 4 & 1 & 24 & 20 & $58(3.1)$ \\
\hline $1-4$ & 13 & 23 & 22 & 30 & 95 & 92 & $275(14.8)$ \\
\hline $5-14$ & 38 & 46 & 52 & 59 & 378 & 298 & $871(46.9)$ \\
\hline $15-44$ & 44 & 25 & 50 & 27 & 273 & 192 & $611(32.9)$ \\
\hline $45+$ years & 4 & 3 & 5 & 7 & 10 & 13 & $42(2.3)$ \\
\hline \multirow[t]{2}{*}{ Total } & $\begin{array}{c}104 \\
(50.7)\end{array}$ & $\begin{array}{c}101 \\
(49.3)\end{array}$ & $\begin{array}{c}133 \\
(51.7)\end{array}$ & $\begin{array}{c}124 \\
(48.3)\end{array}$ & $\begin{array}{c}780 \\
(55.9)\end{array}$ & $\begin{array}{c}615 \\
(44.1)\end{array}$ & \multirow[t]{2}{*}{1857} \\
\hline & \multicolumn{2}{|c|}{205} & \multicolumn{2}{|c|}{257} & \multicolumn{2}{|c|}{1395} & \\
\hline
\end{tabular}

Table 2: Distribution of chickenpox cases by the month among the military community and their families in Taif - KSA over three years period (May 2005 - April 2008)

\begin{tabular}{|c|c|c|c|c|}
\hline MONTH & $\begin{array}{l}\text { First } \\
\text { Year }\end{array}$ & $\begin{array}{l}\text { Second } \\
\text { Year }\end{array}$ & $\begin{array}{l}\text { Total cases for the first two years } \\
\text { (\%) }\end{array}$ & $\begin{array}{l}\text { THIRD } \\
\text { YEAR }\end{array}$ \\
\hline May & 35 & 41 & $76(16.4)$ & 64 \\
\hline June & 24 & 31 & $55(11.9)$ & 23 \\
\hline July & 17 & 25 & $42(9.1)$ & 33 \\
\hline August & 18 & 21 & $39(8.4)$ & 23 \\
\hline September & 11 & 7 & $18(3.9)$ & 44 \\
\hline October & 5 & 5 & $10(2.2)$ & 57 \\
\hline November & 6 & 4 & $10(2.2)$ & 109 \\
\hline December & 2 & 9 & $11(2.4)$ & 99 \\
\hline January & 5 & 11 & 16 (3.5) & 303 \\
\hline February & 7 & 6 & $13(2.8)$ & 165 \\
\hline March & 30 & 42 & $72(15.6)$ & 281 \\
\hline April & 45 & 55 & $100(21.6)$ & 194 \\
\hline TOTAL & 205 & 257 & $462(100)$ & 1395 \\
\hline
\end{tabular}




\section{REFERENCECS}

1. Wharton M. The epidemiology of varicella-zoster virus infection. Infect Dis Clin North Am. 1996; 10: 57181.

2. Galil K, Brown C, Lin F, Seward J. Hospitalization for varicella in the United States, 1988 to 1999. Pediatr Infect Dis J. 2002; 21: 931-4.

3. Choo PW, Donahue JG, Manson JE, Platt R. The epidemiology of varicella and its complications. J Infect Dis. 1995; 172: 706-12.

4. Sullivan-Bentz M. Varicella; to be vaccinated or not to be: that is the question. Canadian Family Physician. 2001; 47: 1368-70.

5. Nurnberg W, Schneeweiss B. Varicella vaccination update. J Dtsch Dermatol Ges. 2006; 4(7): 540-4.

6. Ministry of Health communicable diseases report. Saudi Arabia: Ministry of Health publications; 2003.

7. Fairley CK, Miller E. Varicella-zoster virus epidemiology: a changing scene. J Infect Dis. 1996; 174 Suppl 3: S 314-9.

8. The Saudi Arabia Information Resource. Ministry of Economy and Planning. Kingdom of Saudi Arabia. (Accessed May $5^{\text {th }}$ 2008) Available from URL: http://www.saudinf.com

9. Almuneef $M$, Memish ZA, Balkhy $\mathrm{HH}$, Alotaibi B, Helmy M. Chickenpox complications in Saudi Arabia: Is it time for routine varicella vaccination? J Infect Dis. 2006; 10: 156-61.
10. aban S, Al-Saigul A, Hamed S. Fiveyear surveillance of chickenpox in Qassim, central Saudi Arabia. Saudi Med J. 2007; 28(5): 808-10.

11. Lowe GL, Salmon RL, Thomas D, Evans M. Declining incidence of chickenpox in the absence of universal childhood immunization. Arch Dis Child. 2004; 89: 966-9.

12. Russell ML, Svenson L, Yiannakoulias N, Schopflocher DP, Virani SN. The changing epidemiology of chickenpox in Alberta. Vaccine. 2005; 23: 5398403.

13. Murray A. Varicella surveillance and policy in the United States and Minnesota. Minn Med. 2007; 90(12): 36-9.

14. Stover B, Bratcher D. Varicellazoster virus: infection, control, and prevention. Am J Infect Control. 1998; 24(3): 369-81.

15. Raddadi A, Osoba AO, Abdullah S, Al-Shareef B. Sero-epidemiological study of varicella zoster virus antibodies among an adolescent and adult Saudi population. Oman Med J. 2000; 16: 14-7.

16. Holmes SJ, Morrow Al, Pickering LK. Child-care practices: effects of social change on the epidemiology of infectious diseases and antibiotic resistance. Epidemiol Rev. 1996; 18: 10-28. 